\title{
Hegel e Freud: a Aufhebung hegeliana na denegação (Verneinung) freudiana
}

\section{Hegel and Freud: the hegelian Aufhebung in the freudian negation (Verneinung)}

\author{
Glauber Ataide \\ Graduando do curso de Filosofia, Universidade Federal de Minas Gerais - UFMG, Belo Horizonte, MG, \\ Brasil.
}

Resumo: Este artigo efetua uma aproximação entre Hegel e Freud, apresentando uma interpretação do conceito freudiano de denegação (Verneinung) através do movimento dialético da Aufhebung hegeliana. Tal leitura, inaugurada pelo filósofo francês Jean hyppolite em um dos seminários de Lacan, parece se justificar não apenas pela própria tessitura ou força explicativa do comentário de hyppolite, mas também por diversos outros pontos de aproximação entre o filósofo alemão e o fundador da psicanálise, o que sugere Hegel como uma das chaves de leitura filosóficas mais apropriadas para diversos conceitos freudianos.

Palavras-chave: Hegel, Freud, Aufhebung, Verneinung, denegação.

\begin{abstract}
This paper performs a comparative reading of Hegel and Freud, presenting an interpretation of the freudian concept of negation (Verneinung) through the dialectical movement of the hegelian Aufhebung. this reading, inaugurated by the french philosopher jean hyppolite in one of Lacan's seminars, seems justified not only because of its own merits or because of its internal coherence, but also due to many other possible connections between the german philosopher and the founder of psychoanalysis, what suggests that Hegel might be one of the most appropriate philosophical reading keys of several freudian concepts.
\end{abstract}

Keywords: Hegel, Freud, Aufhebung, Verneinung, negation. 


\section{Introdução}

A investigação dos pressupostos teóricos implicados nas principais categorias psicanalíticas já produziu fecundas aproximações com a filosofia. Embora o próprio Freud não tenha elaborado uma fundamentação ou sistematização filosófica de sua obra, tanto seus conceitos quanto a dinâmica do psiquismo por ele propostos mostram-se plenos de insights que receberam tal tratamento por vários de seus comentadores, filósofos e psicanalistas.

Freud, com a constituição da psicanálise, "circunscreveu algumas problemáticas teóricas que foram fundamentais para a filosofia" (BIRMAN, 2003, p. 7), ao mesmo tempo que a psicanálise também teve que levar em consideração diversas ponderações críticas formuladas pela filosofia.

Não se pode atribuir uma única filiação filosófica à psicanálise. Se alguns autores interpretam a epistemologia psicanalítica como essencialmente kantiana $^{1}$ (SANDLER, 1997, p. 19), outros, por sua vez, encontram em Freud inequívocas influências de Schopenhauer, enquanto que, para outros, certos conceitos psicanalíticos parecem mais bem interpretados à luz de Hegel (GARCIA-ROZA, 2008, p. 276).

Neste artigo buscaremos uma aproximação entre Hegel e Freud, apresentando uma interpretação hegeliana do conceito freudiano de Verneinung. Tal leitura, inaugurada pelo filósofo francês Jean Hyppolite em um dos seminários de Lacan, parece se justificar não apenas pela própria tessitura ou força explicativa do comentário de Hyppolite, mas também por diversos outros pontos de aproximação entre Hegel e Freud ${ }^{2}$, o que reforça e fundamenta o emprego de Hegel como chave de leitura apropriada para diversos pressupostos freudianos.

Sabe-se que Freud nunca leu Hegel (BUTLER, 1976, p. 506). No entanto, não se trata, como afirma Paul Ricoeur, de "colocar Freud em Hegel e Hegel em Freud, e tudo confundir" (RICOEUR, 1965, p. 374). Trata-se, antes, de tentar localizar traços que não encontraram na teoria psicanalítica elaboração sistemática, embora tenham, na prática analítica, valor operatório evidente (RICOEUR, 1965, p. 375).

\section{A Aufhebung hegeliana}

Aufhebung é um dos conceitos fundamentais da filosofia hegeliana (GARCIA-ROZA, 2008 , p. 280). Este substantivo é derivado do verbo alemão aufheben, o qual tem pelo menos três significados distintos que nos interessam: 1) negar (no sentido de anular ou cancelar, como quando suspendemos ou cancelamos um passeio por causa do mau tempo), 2) preservar e também 3) elevar a um nível superior. Hegel foi inovador ao utilizar o substantivo Aufhebung para significar não apenas um destes sentidos de cada vez, mas os três ao mesmo tempo (KONDER, 1984, p. 26). Devido a esta particularidade da língua alemã, a Aufhebung é sempre um problema de tradução. No Brasil, Paulo Meneses optou pelo termo suprassunção. No entanto, sem que se conheça esta particularidade do uso do termo em Hegel, não se pode inferir que

\footnotetext{
${ }^{1}$ Bion, por exemplo, apesar de não ser kantiano, cita diversas vezes a frase de Kant "intuição sem conceito é cega; conceito sem intuição é vazio", além de se valer da distinção entre fenômeno e númeno para se referir a uma realidade última que não está ao nosso alcance (REZENDE, 2000, p. 69-75).

2 Paul Ricoeur (apud BUTLER, 1976, p. 506) afirma que é possível encontrar correspondências entre a dialética hegeliana e a teoria psicanalítica do desenvolvimento sexual. Clark Butler (1976, p. 507), por sua vez, afirma que o método de associação livre guarda certa semelhança com o método fenomenológico empregado por Hegel em sua Fenomenologia do espírito. E, neste mesmo artigo, Butler efetua uma detalhada comparação entre os estágios da dialética da consciência e da autoconsciência na Fenomenologia do espírito, de Hegel, e as fases do desenvolvimento psicossexual individual, tendo em vista que, tanto para Hegel quanto para Freud, a ontogênese repete a filogênese, isso é, o desenvolvimento da espécie é replicado em cada um de seus membros. (BUTLER, 1976, p. 514)
} 
ele englobe ao mesmo tempo os três significados, de modo que o próprio Hegel - e também Paulo Meneses, ao introduzir esse neologismo em sua tradução - explica longamente o significado particular que dá à palavra. Para demonstrar como tal conceito é articulado na obra de Hegel, vamos nos reportar à sua ocorrência mais clara, que é no início de seu sistema.

Em sua Ciência da Lógica, Hegel pretende dar um novo começo à filosofia, sem pressupostos. Isso era necessário, pois Kant, ao tentar deduzir as categorias do entendimento simplesmente tomando as categorias aristotélicas como pressupostos, sem justificá-las ou mostrar sua interconexão lógica, não havia sido suficientemente crítico (SINNERBRINK, 2007, p. 23). Para isso, Hegel recorre então ao que se pode identificar de mais fundamental, que é o ser (Sein). O puro ser é o início, pois é tanto puro pensamento quanto o imediato simples e indeterminado (HEGEL, 1970, p. 182), sendo, assim, apenas abstração pura, ou seja, considerado de forma imediata e indeterminada, é o negativo absoluto, o nada (Nichts). Mas o nada é, pois, caso não fosse, não seria indeterminado. E o nada, como este imediato e indeterminado, igual a si mesmo, é também o mesmo que o puro ser. Por isso afirma Hegel: "o ser e o nada são o mesmo". Ambos são logicamente inseparáveis, e cada um é o que é apenas em virtude do desaparecimento do outro, de modo que a verdade de ambos é o vir-a-ser (Werden) (HEGEL, 1970, p. 188).

Tentemos explicitar este movimento. Ser e nada são definidos por sua pura indeterminação, mas são categorias distintas ao mesmo tempo quanto ao seu significado. Obviamente queremos sempre dizer coisas diferentes quando usamos os termos "ser" e "nada", mas esta diferença não pode realmente ser articulada, de modo que Hegel lança o desafio: "Que aqueles que insistem que ser e nada são diferentes, que ataquem o problema de dizer em que consiste a diferença" (SINNERBRINK, 2007, p. 23).

Segundo Hegel (1970, p. 188), a afirmação de que "o ser e o nada são o mesmo" parece à representação ou ao entendimento tão paradoxal, "que talvez ela nem seja levada a sério". No entanto, o filósofo de Jena afirma deduzir sua unidade de forma puramente analítica, isso é, tudo é extraído do que já está contido no conceito, sem trazer elementos adicionais, externos. Pois, se o ser é o puro começo, nada existe fora

dele, e tudo deve estar contido apenas nele. ${ }^{3}$

O conflito entre essas categorias, que são indistinguíveis, mas ao mesmo tempo opostas quanto ao significado, só pode ser resolvido ao se avançar para o vir-a-ser, o qual, enquanto categoria "superior" e mais complexa, engloba tanto o ser quanto o nada, isso é, incorpora o desvanecer do ser no nada como aspectos suprassumidos de seu movimento. E esta passagem, segundo Hegel, é um movimento exemplar da Aufhebung (SINNERBRINK, 2007, p. 24).

Ilustremos ainda com um exemplo mais concreto: o trabalho, ou a transformação da natureza pelo homem. Para fazer um pão é necessário trigo, o qual se encontra em sua forma bruta na natureza. Mas para que ele chegue à forma de pão, essa matéria-prima deve ser negada, isso é, destruída em sua forma natural. No entanto, ao ser transformado em pasta, o trigo é preservado, ou seja, ainda está lá enquanto trigo. Através da atividade humana ele é então levado ao forno e elevado a um nível superior, sendo o seu resultado o pão. Assim, neste processo vemos os três momentos: o trigo é negado (em seu estado de natureza), preservado e elevado a um nível superior. O trabalho, ou a transformação da natureza pelo homem, é um exemplo de um processo essencialmente dialético, de uma Aufhebung (KONDER, 1984, p. 27).

\footnotetext{
${ }^{3}$ Este movimento nos mostra, entre outras coisas, que a filosofia hegeliana não avança por meio da postulação padronizada de "tese-antítese-síntese". Este método, praticado por Fichte, é falsamente atribuído a Hegel, mas na verdade não tem a ver com o desenvolvimento de seu sistema (DUDLEY, 2007, p. 164).
} 


\section{A Aufhebung freudiana na Verneinung}

O conceito psicanalítico de denegação, ou Verneinung, recebe seu tratamento mais extensivo por Freud em seu artigo Die Verneinung. O substantivo Verneinung deriva do verbo verneinen, o qual corresponde, em português, a "negar" ou "denegar". Em alemão, este verbo evoca a ideia de negar rebatendo algo com um "não" (Nein). A melhor tradução seria "denegar", pois ao traduzir-se verneinen por "negar", perde-se a característica de simultaneamente evocar a explicitação do advérbio "não" e rejeitar um conteúdo apresentado ao sujeito (HANNS, 1996, p. 318). Segundo Hanns (1996, p. 314), o termo Verneinung é geralmente empregado no contexto da escuta e da interpretação que o analista faz das falas do paciente, e geralmente é utilizado na obra de Freud pareado com sua antítese, Bejahung (afirmação).

Segundo Danon-Boileau (2002, p. 1234),

[...] a denegação designa um processo psíquico que permite ao sujeito formular negativamente o conteúdo de um desejo inconsciente", isso é, "o conteúdo do desejo encontra uma expressão consciente, mas o sujeito continua a pensar que esse desejo não lhe pertence.

Freud derivou tal formulação da análise dos discursos de seus pacientes. Ele percebeu como um determinado conteúdo é capaz de ganhar expressão consciente sob a condição de, ao mesmo tempo, ser negado: "Você pensará agora que eu quero dizer algo ofensivo, mas não é minha intenção". Este exemplo expressaria, segundo Freud, apenas a rejeição de um pensamento emergente através da projeção. Outro exemplo seria algo do tipo: "Você quer saber quem pode ser a pessoa no sonho. Não é minha mãe", ao que Freud, então, corrige: "Portanto, é sua mãe". Neste caso é como se o paciente tivesse dito: "Eu de fato associei esta pessoa à minha mãe, mas eu não quero ceder a esta associação" (FREUD, 1955, p. 15).

Uma maneira confortável, segundo Freud, de tentar esclarecer um conteúdo recalcado é sempre perguntando: "O que você considera como o menos provável naquela situação? O que, na sua opinião, estava mais longe de você na época?" (FREUD, 1955 , p. 11). Sendo o paciente capaz de nomear aquilo em que ele menos acreditaria, o que estaria mais distante dele, ele então quase sempre admite o verdadeiro conteúdo.

Uma representação recalcada pode, portanto, ser levada ao consciente, mas sob a condição de que seja denegada. A denegação é uma forma de trazer o recalcado ao conhecimento. Ela é, segundo Freud, uma supressão (Aufhebung) do recalcamento, mas não uma aceitação (Annahme) do recalcado. Segundo Garcia-Roza (2008, p. 282),

[...] na medida em que o paciente formula o conteúdo do pensamento recalcado, apesar de negar que seja expressão do seu desejo, há uma suspensão (Aufhebung) do recalcamento - posto que o recalcado pôde ascender à consciência -, mas permanece o essencial do recalcamento, já que o conteúdo é negado.

Segundo Hyppolite (1989, p. 49), aqui começa algo realmente extraordinário na análise de Freud, com um alcance filosófico prodigioso.

Apresentar o seu ser num modo de não sê-lo é realmente do que se trata nesta Aufhebung do recalcamento, que não é uma aceitação do recalcado [...]

afirma o filósofo francês. Se recalcamento significa inconsciência, não haveria mais recalcamento quando se diz: "Eis o que não sou”, já que isso é consciente. Mas, como Freud afirma, o recalcamento subsiste quanto ao essencial.

Neste ponto, afirma Freud, pode-se ver como a função intelectual se separa da atividade (Vorgang) afetiva. Com a ajuda da denegação um resultado do recalcamento é desfeito, o qual tentava evitar a emergência de um determinado conteúdo ao nível de consciência. Disso resulta uma aceitação (Annahme) do recalcado pela continuação do essencial no recalcamento. Às vezes é também possível, no trabalho analítico, vencer a própria denegação e alcançar uma completa aceitação intelectual do recalcado, 
mas mesmo que o analista indique ao paciente sua artimanha, e este seja obrigado a aceitar o que há pouco negava, Freud afirma: "nem por isso o recalcamento é suspenso (aufgehoben)" (GARCIA-ROZA, 2008, p. 282).

Segundo Jean Hyppolite (1989, p. 51), pode-se esquematizar este processo da seguinte maneira:

Primeira etapa: eis o que não sou. Daí concluiu-se o que sou. O recalcamento subsiste sempre sob a forma da denegação.

Segunda etapa: o psicanalista obriga-me a aceitar em minha inteligência o que negava ainda há pouco; e Freud acrescenta, após um travessão e sem maiores explicações: “O processo do recalcamento não está, com isso, propriamente suspenso (aufgehoben)".

O que, segundo Hyppolite $(1989$, p. 51), parece profundo nesta descoberta de Freud, é que se o psicanalisado aceita o apontamento do analista, volta então à sua denegação e o recalcamento ainda está ali. O que acontece, então, é chamado por Hyppolite de negação da negação: "Literalmente, o que aparece aqui é a afirmação intelectual, mas apenas intelectual, enquanto negação da negação".

É tarefa da função de juízo (Urteilsfunktion) intelectual, segundo Freud, afirmar ou negar conteúdos de pensamento. Denegar algo no juízo significa, essencialmente: "Isso é algo que eu gostaria de recalcar." A condenação (Verurteilung) é a substituição intelectual do recalcamento, o seu "não" um sinal do mesmo, um certificado de procedência, algo como um "made in Germany" (FREUD, 1955, p. 12). Através dos juízos de denegação o pensamento se faz livre das limitações do recalcamento.

Neste movimento dialético da Verneinung evidenciam-se também os vários níveis de negação e afirmação em Freud. A negação aqui analisada é aquela que se faz através do símbolo de negação, o "não" da frase (como em "a pessoa do sonho não é a minha mãe") (GARCIA-ROZA, 2008, p. 283). Mas há em Freud várias formas de negação, desde a negação primordial, Ausstossung (uma expulsão, relacionada ao princípio de prazer e ao movimento de introjetar o que é bom e expulsar o que é ruim), até a denegação (Verneinung). O que está em jogo, portanto, não é apenas uma oposição afirmação \negação, mas

[...] uma série de negações e negações de negações que engendram um processo no qual o afirmado e o negado não são excluídos pela negação seguinte, mas superados (aufgehoben)" (GARCIA-ROZA, 2008, p. 286).

\section{Conclusão}

Embora Freud tenha evitado estabelecer qualquer conexão com a filosofia a fim de manter o que ele acreditava ser uma "respeitabilidade científica" da psicanálise, algumas aproximações entre ambos não parecem meros acasos. Butler (1976, p. 507) considera que tais aproximações são, na verdade, uma confirmação tanto daquilo que eles descobriram quanto da grandeza dos próprios descobridores.

Além da afinidade conceitual entre a Aufhebung hegeliana e a freudiana que analisamos, outro importante ponto de aproximação que pode ser explorado são as chamadas "dualidades" freudianas. Segundo Garcia-Roza (2008, p. 276), o que se convencionou chamar "dualismos" freudianos, como, por exemplo, o dualismo de princípios (princípio de prazer \princípio de realidade), o dualismo tópico (inconsciente \consciente) e o dualismo pulsional (pulsões de vida \pulsões de morte) são muito mais dualidades do que dualismos propriamente ditos. A diferença entre "dualismo" e "dualidade" seria que, 
[...] no dualismo, as entidades implicadas preexistem e são exteriores às relações que estabelecem, enquanto que numa dualidade, os elementos que a formam só existem na e pela relação estabelecida (GARCIA-ROZA, 2008, p. 276).

Desta forma, as dualidades em Freud seriam mais bem pensadas segundo um modelo hegeliano do que segundo um modelo cartesiano, pois Hegel também pensa em termos de dualidades, e não de dualismos.

O conceito hegeliano de Aufhebung, o qual analisamos em relação à Verneinung de Freud, pode ainda ser explorado em relação com outra noção freudiana: a de sublimação. Segundo Butler (1976, p. 517), na "transcendência" (Aufhebung) hegeliana o passado é tanto negado quanto preservado em um nível superior. Em certo sentido, o passado permanece vivo em sua transcendência, e no fundo não se renuncia a nada de forma cabal, completa. Isso seria muito similar à maneira com que a sublimação transfigura o erotismo sem aniquilá-lo. Através da sublimação é dada satisfação parcial, indireta às pulsões eróticas. Também aqui o conteúdo negado no primeiro movimento de negação reaparece depois que a própria negação é negada, mas dessa vez transformado, elevado a um nível superior.

Ainda outro processo psíquico que também admite uma aproximação com a Aufhebung hegeliana é o da formação do sintoma. Segundo Wilhelm Reich (1934, p. 25), o sintoma neurótico surge quando o eu (Ich) recalca uma moção pulsional (Triebregung). Mas este recalcamento, por si só, não gera ainda nenhum sintoma, sendo necessário, para isso, que a pulsão recalcada rompa (durchbreche) o recalcamento e se manifeste novamente, mas, agora, como sintoma. O sintoma engloba tanto a moção pulsional quanto a própria defesa $(A b w e h r)$; isso é, ele contém dentro de si ambas as tendências opostas, unidas no mesmo fenômeno. O sintoma é a negação da negação (REICH, 1934, p. 26).

A intenção de Reich, no entanto, é aproximar Freud não de Hegel, mas sim de Marx. Mas tendo sido o método marxista tomado de Hegel - ou pelo menos o seu núcleo racional, como afirma Marx -, isso abre todo um novo campo de possibilidades. Estudos comparativos de Hegel e Freud prometem, portanto, resultados intrigantes, haja vista a enorme influência de Hegel sobre toda a filosofia ocidental posterior (ZARE'I; SHAGHOOL, 2014, p. 1955). Pois, como afirma Merleau-Ponty:

Hegel está na origem de tudo que se fez de grande há um século - por exemplo, do marxismo, de Nietzsche, da fenomenologia alemã, da psicanálise; ele inaugura a tentativa de explicar o irracional e integrá-lo a uma razão ampliada que continua sendo a tarefa do século (MERLEAU-PONTY, 1966, p. 75).

Correspondência: Glauber Ataide. Universidade Federal de Minas Gerais - UFMG, Av. Pres. Antônio Carlos, 6627, Pampulha, 31270-901, Belo Horizonte, MG, Brasil. E-mail: glauberataide@gmail.com Conflito de interesses: Nenhum.

Todos os autores leram e aprovam a versão final submetida a revista Em curso. 


\section{Bibliografia}

BIRMAN, J. Freud e a filosofia. Rio de Janeiro: Jorge Zahar, 2003.

BUTLER, C. Hegel and Freud: a comparison. Philosophy and Phenomenological Research, Providence, v. 36, n. 4, p. 506-522, 1976.

DANON-BOILEAU, L. Denegação. In: MIJOLLA, A. Dicionário Internacional de Psicanálise. Rio de Janeiro: Imago, 2002. v. 2.

DUDLEY, W. Understanding German idealism. Stocksfield: Acumen, 2007.

FREUD, S. Die Verneinung. London: Imago Publishing House, 1955. (Sigmund Freud Gesammelte Werke, v. 14)

GARCIA-ROZA, L. A. Introdução à metapsicologia freudiana. 7. ed. Rio de Janeiro: Jorge Zahar, 2008. Vol. 3.

HANNS, L. Dicionário comentado do alemão de Freud. Rio de Janeiro: Imago, 1996.

HEGEL, G. W. F. Enzyklopädie der philosophischen Wissenchaften im Grundrisse. Frankfurt: Suhrkamp Verlag, 1970. (Georg Wilhelm Friedrich Hegel Werke, v. 2).

HYPPOLITE, J. Ensaios de psicanalise e filosofia. Tradução de André Telles. Rio de Janeiro: Livrarias Taurus-Timbre Editores, 1989.

KONDER, L. O que é dialética? 10. ed. São Paulo: Editora Brasiliense, 1984.

MERLEAU-PONTY, M. Sens et non-sens. 5. ed. Paris: Nagel, 1966.

SANDLER, P. C. As origens da psicanálise na obra de Kant. Rio de Janeiro: Imago, 1997. (A apreensão da realidade psíquica, v. 3).

SINNERBRINK, R. Understanding Hegelianism. Stocksfield: Acumen, 2007.

REICH, W. Dialektischer materialismus und Psychoanalyse. Kopenhagen: Verlag für Sexualpolitik, 1934.

REZENDE, A. M. O paradoxo da psicanálise: uma ciência pós-paradigmática. São Paulo: Via Lettera, 2000.

RICOEUR, P. Da interpretação: ensaio sobre Freud. Tradução de Hilton Japiassu. Rio de Janeiro: Imago, 1965.

ZARE'I, A.; SHAGHOOL, Y. Deconstructing the psychoanalyst of Philosophy. Mediterranean Journal of Social Sciences, v. 5, n. 23, p. 1949-1955, 2014. 